\title{
PROMOÇÃO DO DESENVOLVIMENTO DE NOGUEIRA- MACADÂMIA COM REGULADORES VEGETAIS VISANDO ENXERTIA PRECOCE
}

\author{
P.R.C. CASTRO ${ }^{1}$ \\ S.R. PENTEADO ${ }^{2}$ \\ E.R. TERAMOTO ${ }^{1}$ \\ C.G.B. DEMÉTRIO \\ N.H. ANZAI ${ }^{3}$
}

RESUMO: O experimento, realizado no Horto Experimental do Departamento de Botânica da Escola Superior de Agricultura "Luiz de Queiroz", teve por finalidade promover o desenvolvimento precoce de porta-enxertos de Macadamia integrifolia visando abreviar a produção de mudas. As plantas de nogueira-macadâmia com 4 meses de idade (120 D.A.S.) foram pulverizadas com ácido giberélico 50, 100,250 e 500 ppm, ácido naftalenacético 50, 100, 250 e 500 ppm, ácido giberélico 100 ppm + ácido naftalenacético $100 \mathrm{ppm}$, além do contro-le. Esses tratamentos foram repetidos aos 181 D.A.S. Determinações periódicas da altura da planta e do diâmetro do caule mostraram que ácido giberélico $500 \mathrm{ppm}$ aplicado 120 D.A.S. promoveu o maior crescimento em altura dos porta-enxertos de nogueira-macadâmia; sendo que ácido giberélico 50 ppm, aplicado 120 e 181 D.A.S. também se

1 Departamento de Botânica - Escola superior de Agricultura "Luiz de Queiroz" / Universidade de São Paulo.

2 CATI - Secretaria da Agricultura do Estado de São Paulo.

3 Departamento de Matemática e Estatistica da Escola Superior de Agricultura "Luiz de Queiroz" da Universidade de São Paulo. 
mostrou eficiente. Pulveriza-ção com ácido giberélico 500 ppm ou ácido giberélico 100 ppm + acido naftalenacético 100 ppm, 120 D.A.S. promoveram o maior aumento precoce no diametro do caule das mudas de Macadamia; sendo que acido giberélico 50 e 250 ppm, aplicado 120 e 181 D.A.S. também se revelaram eficientes. Termos para Indexação: Macadamia integrifolia, desenvolvimento precoce, reguladores vegetais.

\section{MACADAMIA-NUT GROWTH PROMOTION WITH GROWTH REGULATORS AIMING EARLX GRAFTING}

ABSTRACT: This study investigates the effects of growth substances on the growth of macadamia-nut rootstocks and the possibility of shortening the period of time plant formation on nursery. Four-month-old rootstocks were sprayed with gibberellic acid 50, 100, 250 and $500 \mathrm{ppm}$, naphtalenacetic acid 50, 100, 250 and $500 \mathrm{ppm}$, gibberellic acid $100 \mathrm{ppm}$ plus naphtalenacetic acid $100 \mathrm{ppm}$, and check treatment. Gibberellic acid 500 ppm applied 120 days after sowing (D.A.S.) promoted increases in plant height, gibberellic acid 50 ppm applied 120 and 181 D.A.S. showed effectiviness too. Spraying with gibberellic acid 500 ppm or gibberellic acid 100 plus naphtalenacetic acid 100 ppm 120 D.A.S. promoted increases in stem diameter, gibberellic acid 50 and 150 ppm applied 120 and 181 D.A.S. showed effectiviness too.

Index Terms: Macadamia integrifolia, early growth, growth regulators.

\section{INTRODUÇÃO}

A nogueira-macadâmia é uma planta de crescimento bastante lento em condiçōes de viveiro, dificultando e onerando a produção de mudas: um dos maiores entraves ao estabeleci- 
mento do cultivo comercial desta importante produtora de nozes em condiçōes brasileiras.

CAMPO-DALL'ORTO et alii (1979) estudaram de forma comparada o desenvolvimento de algumas progênies de Macadamia integrifolia visando a obtenção de melhores porta-enxertos.

PAREJA (1981) considerou que o anelaento do garfo, realizado 30 a 60 dias antes da enxertia, aumentou o sucesso da enxertia. Este mesmo autor constatou que a enxertia em "inglês simples" mostrou-se mais vantajosa que a "fenda cheia", "fenda lateral" e "inglês complicado". CAMPO-DALL'ORTO et alii (1988) verificaram que a garfagem tipo "inglês simples", executada no topo do porta-enxerto bem novo e tenro, com 6 meses de idade, apresentou alta eficiência de pegamento $(94,8 \%)$, com relação ao executado sobre o porta-enxerto com 20 meses $(66,8 \%)$. Esse resultado pode corrigir alguns dos principais problemas na produção de mudas de nogueira-macadâmia: demora de 2 a 3 anos, escassez de garfos para a enxertia com mais de $7 \mathrm{~mm}$ de diâmetro e dificuldades na execução de cortes uniformes.

AHMED \& KHAN (1964) estudaram os efeitos de diferentes concentrações de ácido giberélico em citros. Pulverizações de limoeiro Rugoso, com 2 semanas de intervalo, promoveram maior crescimento em altura (100 ppm), sendo que as concentrações de 25 e 100 ppm causaram aumento no diametro do caule.

Aplicaçōes de acido giberélico 25, $50,75,100$ e 200 ppm, em intervalos quinzenais, no porta-enxerto laranja Azeda com 8 meses de idade, promoveram incrementos no desenvolvimento da ordem de 14 a $39 \%$ (SIDAHMED, 1978).

Pulverizaçōes de ácido giberélico ou de ácido giberélico + chlormequat em portaenxertos de mangueira promoveram aumentos significativos na altura da planta e no diâmetro do caule (RAMOS, 1980). 
COELHO et alii (1983) aplicaram ácido giberélico $50,100,150$ e 200 ppm, em plantas de citros com 4 meses de idade, visando reduzir o período de formação de muda. As concentrações utilizadas promoveram aumentos em altura de 8 , 37,59 e $63 \%$, respectivamente. O diâmetro do caule não foi afetado pelos tratamentos com ácido giberélico.

CANET et alii (1983), visando reduzir o período de permanência da nogueira-macadâmia em viveiro, realizaram aplicaçōes de diferentes concentrações e misturas de ácido giberélico, ácido indolilacético e benziladenina. Maior estímulo no crescimento em altura foi promovido por ácido giberélico $500 \mathrm{ppm}+$ ácido indolilacético $500 \mathrm{ppm}$, indicando a ação sinergética. observou-se que o ácido giberélico é o regulador vegetal que promove maior crescimento longitudinal nos porta-enxertos, o que sugere que os níveis endógenos desse hormônio na nogueira-macadâmia devem ser relativamente baixos, que explicariam resposta mais evidente para a concentração mais alta (500 ppm). o ácido giberélico foi o regulador vegetal que mais estimulou o aumento no diâmetro do caule do porta-enxerto (cerca de $37 \%$ ), o que fez com que o mesmo estivesse pronto para sua enxertia 2,5 meses antes do controle. Duas aplicações, em plantas com 4 meses, e outra 45 dias mais tarde, mantiveram um crescimento praticamente constante; sendo que tanto a benziladenina como as misturas triplices favoreceram o desenvolvimento das brotações laterais, afetando negativamente o crescimento da haste principal da nogueira-macadámia.

Este trabalho teve por objetivo promover o desenvolvimento precoce do porta-enxerto da nogueira-macadámia, com reguladores vegetais, com a finalidade de se efetuar enxertia precoce, reduzindo o tempo de produção da muda. 


\section{MATERIAL E MÉTODOS}

o experimento foi realizado em condiçōes de viveiro aberto, no Horto Experimental do Departamento de Botânica da Escola Superior de Agricultura "Luiz de Queiroz"/USP - Campus de Piracicaba-sP.

Mudas uniformes de Macadamia integrifolia Maid. e Bet., com 4 meses de idade, portanto 120 dias após a semeadura (D.A.S.) foram pulverizadas com ácido giberélico $\left(\mathrm{GA}_{3}\right)$ $50,100,250$ e 500 ppm, ácido naftalenacético (NAA) $50,100,250$ e 500 ppm, com ácido giberélico $100 \mathrm{ppm}+$ ácido naftalenacético $100 \mathrm{ppm}$, além do controle, Esses tratamentos foram repetidos aos 181 D.A.S.

A altura (cm) a partir do colo e o diâmetro do caule (mm) tomado a $5 \mathrm{~cm}$ do colo das plantas, foram determinados aos 120 $(18.11 .87), 135(03.12 .87), 150(18.12 .87), 181$ $(18.01 .88), 196(02.02 .88)$ e $211(17.02 .88)$ D.A.S.

o delineamento estatístico usado foi inteiramente casualizado, constituindo-se de dez tratamentos com dez repetições, sendo cada repetição correspondente a um porta-enxerto, plantado em saco plástico preto com capacidade para 10 litros de terra. Foi realizada anáíise de variância e aplicado o teste Tukey (5\%) em cada data de determinação dos parâmetros de crescimento.

\section{RESULTADOS E DISCUSSÃO}

Pelas Tabelas 1 e 2 notamos que as mudas do porta-enxerto de nogueira-macadâmia apresentavam-se uniformes aos 4 meses (120 D.A.S.), nāo revelando diferenças marcantes tanto na altura como no diámetro das plantas. Nesta data foi realizada a primeira aplicação dos reguladores vegetais. Esses produtos quimicos não afetaram os parámetros determinados 
Tabela 1 - Altura (cm) das plantas de Macadamia integrifolia, determinada em diferentes épocas, submetidas a aplicação de reguladores vegetais 120 e 181 dias após a semeadura (D.A.S.). Valores dos testes F, Tukey (5\%) e coeficiente de variação.

\begin{tabular}{|c|c|c|c|c|c|c|}
\hline \multirow{2}{*}{ Tratamento } & \multicolumn{5}{|c|}{ D.A.S. } & \multirow[b]{2}{*}{211} \\
\hline & 120 & 135 & 150 & 181 & 196 & \\
\hline Controle & 24,14 & 26,45 & $27,90 a b$ & $30,85 \mathrm{ab}$ & $33,16 \mathrm{abc}$ & $34,70 \mathrm{ab}$ \\
\hline $\mathrm{GA}_{3} 50$ & 23,35 & 26,40 & $29,30 \mathrm{ab}$ & $32,80 \mathrm{ab}$ & $35,90 \mathrm{ab}$ & $37,20 a$ \\
\hline $\mathrm{GA}_{3} 100$ & 22,20 & 25,50 & $27,30 \mathrm{ab}$ & $29,95 \mathrm{ab}$ & $32,27 \mathrm{abc}$ & $33,50 \mathrm{ab}$ \\
\hline $\mathrm{GA}_{3} 250$ & 23,10 & 26,30 & $28,55 \mathrm{ab}$ & $31,10 \mathrm{ab}$ & $35,65 \mathrm{ab}$ & $36,00 \mathrm{ab}$ \\
\hline $\mathrm{GA}_{3} 500$ & 23,35 & 27,70 & $30,80 a$ & $33,70 a$ & $37,10 \mathrm{a}$ & $39,20 a$ \\
\hline NAA 50 & 25,40 & 27.25 & $29,45 a b$ & $32,40 \mathrm{ab}$ & $34,15 \mathrm{abc}$ & $35,80 \mathrm{ab}$ \\
\hline NAA 100 & 23,15 & 25,10 & $26,25 a b$ & $30,40 a b$ & $31,67 \mathrm{abc}$ & $33,40 \mathrm{ab}$ \\
\hline NAA 250 & 23,10 & 24,15 & $24,65 \mathrm{~b}$ & $26,85 \mathrm{~b}$ & $27,78 \quad c$ & $28,80 \mathrm{~b}$ \\
\hline NAA 500 & 23,15 & 24,30 & $24,95 \mathrm{~b}$ & $27,40 \mathrm{~b}$ & $28,30 \mathrm{bc}$ & $28,80 \mathrm{~b}$ \\
\hline $\begin{array}{l}\mathrm{GA}_{3}+\mathrm{NAA} \\
(100 \mathrm{ppm})\end{array}$ & 24,60 & 27,10 & $28,70 \mathrm{~b}$ & $32,00 \mathrm{~b}$ & $34,80 a b c$ & $35,85 \mathrm{ab}$ \\
\hline$F($ trat.) & $1,30^{\text {ns }}$ & $1,43^{\text {ns }}$ & $3,02 * \star$ & $2,46 \star$ & $3,42 \star \star$ & $3,47 \star \star$ \\
\hline C.V. (t) & 11,92 & 12,42 & 13,10 & 14,60 & 16,21 & 16,66 \\
\hline
\end{tabular}

na năo significativo

* significativo ao nivel de $5 \%$ de probabilidade ** significativo ao nivel de 18 de probabilidade

OBS: Valores seguidos de letras diferentes, dentro da coluna, diferem significamente pelo Teste Tukey (5\%). 
Tabela 2 - Diâmetro do caule das plantas de Macadamia integrifolia, determinado em diferentes épocas, subme-

tidas a aplicaçāo de reguladores vegetais 120 e 181 dias após a semeadura (D.A.S.). Valores dos testes F, Tukey (5q) e coeficiente de variação.

\begin{tabular}{|c|c|c|c|c|c|c|}
\hline \multirow{2}{*}{ Tratamento } & \multicolumn{5}{|c|}{ D.A.S. } & \multirow[b]{2}{*}{211} \\
\hline & 120 & 135 & 150 & 181 & 196 & \\
\hline Controle & 6,10 & 6,53 & $6,70 \mathrm{ab}$ & $7,10 \mathrm{ab}$ & $7,38 \mathrm{abc}$ & $7,76 \mathrm{abc}$ \\
\hline $\mathrm{GA}_{3} 50$ & 5,84 & 6,41 & $6,66 \mathrm{ab}$ & $7,40 a b$ & $7,78 \mathrm{ab}$ & $8,19 \mathrm{ab}$ \\
\hline $\mathrm{GA}_{3} 100$ & 5,78 & 6,32 & $6,36 \mathrm{ab}$ & $6,98 \mathrm{ab}$ & $7,39 \mathrm{abc}$ & $7,95 \mathrm{abc}$ \\
\hline $\mathrm{GA}_{3} 250$ & 5,52 & 6,57 & $6,81 \mathrm{ab}$ & $7,53 \mathrm{ab}$ & $7,68 \mathrm{ab}$ & $8,28 a b$ \\
\hline $\mathrm{GA}_{3} 500$ & 5,96 & 6,39 & $7,14 \mathrm{a}$ & $8,06 a$ & $8,23 a$ & $8,77 a$ \\
\hline NAA 50 & 5,52 & 6,68 & $6,82 \mathrm{ab}$ & $7,45 \mathrm{ab}$ & $7,65 \mathrm{abc}$ & $7,95 \mathrm{abc}$ \\
\hline NAA 100 & 5,40 & 5,87 & $6,31 \mathrm{ab}$ & $6,70 \mathrm{~b}$ & $6,81 \mathrm{bc}$ & $7,11 \mathrm{bc}$ \\
\hline NAA 250 & 5,64 & 6,01 & $6,24 a b$ & $6,75 \mathrm{~b}$ & $6,92 \mathrm{bc}$ & $7,08 \mathrm{bc}$ \\
\hline NAA 500 & 5,63 & 5.85 & $5,96 \mathrm{~b}$ & $6,37 \mathrm{~b}$ & 6,37 & 6,64 \\
\hline $\begin{array}{l}\mathrm{GA}_{3}+\mathrm{NAA} \\
(100 \mathrm{ppm})\end{array}$ & 6,11 & 6,56 & $7,19 a$ & $7,93 \mathrm{a}$ & $8,04 a b$ & $8,60 a$ \\
\hline$F($ trat. $)$ & $1,16^{\mathrm{ns}}$ & $1,80^{\text {ns }}$ & $2.52 \star \star$ & $4,62 \star$ & $4,21 \star \star$ & $5,11 \star \star$ \\
\hline C.V. (安) & 13,24 & 11,31 & 11,98 & 11,10 & 12,01 & 12,40 \\
\hline
\end{tabular}

ns não significativo

* significativo ao nivel de $5 \%$ de probabilidade

** significativo ao nível de $1 \%$ de probabilidade

OBS: Valores seguidos de letras diferentes, dentro da coluna, diferem significamente pelo Teste Tukey (5\%). 
15 dias depois, pois aos 135 D.A.S. também não observamos diferenças entre os tratamentos (Tabelas 1 e 2 ). Os reguladores vegetais geralmente atuam sobre as plantas perenes após periodos mais longos de tempo.

Aos 150 D.A.S. observamos um aumento no crescimento em altura das plantas tratadas com ácido giberélico 500 ppm, em relação àquelas pulverizadas com ácido naftalenacético 250 e 500 ppm (concentraçōes provavelmente superiores aos níveis ótimos, com relação a concentração endógena de auxina do caule, levando a síntese de etileno de ação retardante no crescimento) e àquelas tratadas com ácido giberélico $100 \mathrm{ppm}+$ ácido naftalenacético $100 \mathrm{ppm}$, de acordo com a Tabela 1. Verificamos a maior eficiência sobre as mudas de nogueira-macadâmia, da concentração mais alta de ácido giberé1 ico.

Conforme a Tabela 2, observamos que aos 150 D.A.S. as plantas tratadas com ácido giberélico $100 \mathrm{ppm}$ + ácido naftalenacético 100 ppm e aquelas pulverizadas com ácido giberélico 500 ppm já mostravam diâmetro do caule superior a $7 \mathrm{~mm}$, diferindo do tratamento com ácido naftalenacético 500 ppm. Essas mudas já estariam aptas para recepção de garfos do enxerto, em função do diâmetro precocemente alcançado (CAMPO-DALL'ORTO et alii, 1988).

As plantas foram novamente pulverizadas com os reguladores vegetais 181 D.A.S. Nesta data, o efeito da primeira aplicação mostrava que as plantas tratadas com ácido giberélico 500 ppm apresentavam altura superior àquelas tratadas com acido naftalenacético 250 e 500 ppm, além de ácido giberélico 100 ppm + ácido naftalenacético $100 \mathrm{ppm}$ (Tabela 1).

A primeira aplicação promoveu, 181 D.A.S., aumento no diâmetro do caule das plantas tratadas com ácido giberélico 500 ppm e ácido giberélico 100 ppm + ácido naftalenacético 100 ppm em relação àquelas pulverizadas 
com ácido naftalenacético 500, 100 e 250 ppm (Tabela 2).

Aos 196 D.A.S. notamos, pela Tabela 1, que o uso do ácido giberélico a 500 ppm promovia o maior crescimento em altura da nogueira-macadâmia em relação aos tratamentos com ácido naftalenacético 250 e 500 ppm. Nesta data, observamos que ácido giberélico $500 \mathrm{ppm}$, ácido giberélico $100 \mathrm{ppm}$ + ácido naftalenacético $100 \mathrm{ppm}$, ácido giberélico 50 e $250 \mathrm{ppm}$, promoveram maior incremento no diâmetro do caule das mudas, em relação àquelas pulverizadas com ácido naftalenacético $500 \mathrm{ppm}$ (Tabela 2). Sob efeito das duas aplicações dos reguladores vegetais, observamos 211 D.A.S. os tratamentos com ácido giberélico 500 e 50 ppm mostraram-se os mais eficientes em promover o crescimento em altura da nogueira-macadâmia em relação aos tratamentos com ácido naftalenacético 250 e $500 \mathrm{ppm}$, responsáveis pelas plantas mais baixas (Tabela 1). CANET et alii (1983) também alcançaram a maior eficiência na promoção do crescimento em altura da nogueira-macadâmia com a concentração mais elevada de ácido giberélico, sugerindo que esta espécie perene possue teores endógenos de giberelina no caule bastante baixos. Nessa data, o diâmetro do caule mostrou-se maior nas plantas tratadas com ácido giberélico 500 ppm e ácido giberélico 100 ppm + ácido naftalenacético 100 ppm, em relação àquelas pulverizadas com ácido naftalenacético 500,250 e $100 \mathrm{ppm}$ (Tabela 2).

\section{CONCLUSÕES}

De acordo com os resultados obtidos, podemos estabelecer as seguintes conclusões:

a) Os tratamentos utilizados não modificam significativamente a altura nem o diametro das plantas de nogueira-macadâmia, com relação ao controle. 
b) O ácido giberélico e o ácido naftalenacético afetam o desenvolvimento do caule de Macadamia integrifolia após períodos superiores a 15 dias após a pulverização com os reguladores vegetais.

c) Ácido giberélico 500 ppm aplicado 120 D.A.S. promove o maior crescimento em altura dos porta-enxertos de nogueira-macadâmia; sendo que ácido giberélico 50 ppm, aplicado 120 e 181 D.A.S. também se mostra eficiente.

d) Aplicação de ácido giberélico 500 ppm ou ácido giberélico $100 \mathrm{ppm}+$ ácido naftalenacético $100 \mathrm{ppm}, 120 \mathrm{D} . \mathrm{A} . \mathrm{S}$. promovem o maior aumento precoce no diâmetro do caule das mudas de nogueira-macadâmia; sendo que esse incremento leva as plantas a atingirem aptidão para enxertia (diâmetro do caule $>7 \mathrm{~mm}$ ) 1 mês antes do controle.

\section{AGRADECIMENTOS}

Ao Prof. MARCOS SILVEIRA BERNARDES, do Departamento de Agricultura da Escola Superior de Agricultura "Luiz de Queiroz"-USP, pela colaboração prestada. 


\section{REFERÊNCIAS BIBLIOGRÁFICAS}

AHMED, S. \& KHAN, M.L. Effects of gibberellic acid on the growth of citrus seedlings. Punjab Fruit Journal, New Delhi, 26/27: 335-41, 1964 .

CAMPO-DALL'ORTO, F.A.; OJIMA, M.; TOMBOLATO, A.F.C.; RIGITANO, O. Desenvolvimento comparativo de algumas progênies de nogueiramacadâmia (Macadamia integrifolia Maiden e Betche) visando a obtençāo de porta-enxertos. In: CONGRESSO BRASILEIRO DE FRUTICULTURA, 5. Pelotas, 1979. Anais. Pelotas, 1979. v.2. p.454-62.

CAMPO-DALL'ORTO, F.A.; OJIMA,M.; BARBOSA, W.; SABINO, J.C.; RIGITANO, O. Enxertia precoce da nogueira-macadâmia. Bragantia, Campinas, $47(2): 195-211,1988$.

CANET, G.; ARIAS, O.; CANET, G. Effecto de vários fitoreguladores sobre el comportamiento em vivero de la macadamia (Macadamia tetraphylla) Costa Rica, Universidad de Costa Rica, p.15-6.

COELHO, Y.S.; OLIVEIRA, A.A.R.; CALDAS, R.C. Efeitos do ácido giberélico $\left(\mathrm{GA}_{3}\right)$ no crescimento de porta-enxertos para citros. Pesquisa Agropecuária Brasileira, Brasilia, 18(11): 1229-32, 1983 .

PAREJA, C.J.M.A. Comparação de diversos métodos de enxertia na propagação da macadâmia (Macadamia integrifolia Maiden \& Betche) em São Paulo. Piracicaba, 1981. 52p. (Mestrado - Escola Superior de Agricultura "Luiz de Queiroz"/USP). 
RAMOS, V.H.V. Efeitos do ácido giberélico e cycocel sobre porta-enxertos de mangueira (Mangifera indica L.) em viveiro. Viçosa, 1980. 117p. (Mestrado-Universidade Federal de Viçosa).

SIDAHMED, O.A. Effects of different levels of gibberellic acid $\left(\mathrm{GA}_{3}\right)$ on growth of sour orange (Citrus aurantium) seedlings. Acta Horticulturae, The Hague, 84: 165-9, 1978 .

Trabalho entregue para publicação em 20.01.91 Trabalho aprovado para publicação em 08.08 .91 